\title{
Pregnancy in transgender men
}

\author{
Kimberley G.S. Thornton MD BKin, Fiona Mattatall MD MSc
}

Cite as: CMAJ 2021 August 23;193:E1303. doi: 10.1503/cmaj.210013

\footnotetext{
Routine care for transgender men should include discussions of

1 fertility goals

Fertility planning for all transgender men, particularly those with a uterus, should be discussed at regular intervals without assumption of type of sexual activity or fertility goals. ${ }^{1}$ For patients aiming for pregnancy, clinicians should discuss both medical and psychosocial expectations from preconception to postpartum. ${ }^{2,3}$
}

\section{Testosterone is not a form of contraception, even in patients who are amenorrheic}

Transgender men with a uterus are at risk of unplanned pregnancy. Limited literature suggests similarly high rates of unplanned pregnancies in this population as in ciswomen and similar uptake of all contraceptive options, from barrier methods to hormonal contraceptives. ${ }^{1}$ Oral contraceptives may be used concurrently with androgenic hormone therapy.

\section{Preconception counselling in transgender men must include} discussion around continuation of testosterone therapy

Testosterone has teratogenic effects; specifically it can cause abnormal urogenital development in a female fetus. Therefore, testosterone should not be used while attempting conception or during pregnancy. ${ }^{1,4}$

\section{4}

\section{Whether pregnant transgender men are at higher risk of} peripartum complications is unknown

No high-quality data are available regarding the incidence of pregnancy complications (e.g., gestational diabetes or hypertension) for transgender men. ${ }^{2}$ Vaginal birth is possible for transgender men, and counselling should include all options to optimize patient agency and birth experience. ${ }^{2,3,5}$ Chestfeeding can be explored postpartum if the patient chooses. ${ }^{2,3}$

\section{Psychosocial support is a critical component of pregnancy care \\ 3 for transgender men}

Few gender-sensitive resources on pregnancy exist for transgender men, but this does not reflect lack of need. ${ }^{2}$ Fears of stigmatization by their community, the wider population and health care providers are prevalent. Inclusive and sensitive care includes attention to pronouns, environment and language (such as "chest" instead of "breast"). 2,3,5

\section{References}

1. Light A, Wang L-F, Zeymo A, et al. Family planning and contraception use in transgender men. Contraception 2018;98:266-9.

2. Light AD, Obedin-Maliver J, Sevelius JM, et al. Transgender men who experienced pregnancy after female-to-male gender transitioning. Obstet Gynecol 2014;124:1120-7.

3. Hoffkling A, Obedin-Maliver J, Sevelius J. From erasure to opportunity: a qualitative study of the experiences of transgemder men around pregnancy and recommendations for providers. BMC Pregnancy Childbirth 2017;17(Suppl 2):332.

4. Krempasky C, Harris M, Abern L, et al. Contraception across the transmasculine spectrum. Am J Obstet Gynecol 2020;222:134-43.

5. Brandt JS, Patel AJ, Marshall I, et al. Transgender men, pregnancy, and the "new" advanced paternal age: a review of the literature. Maturitas 2019;128:17-21.

Competing interests: Fiona Mattatall is co-chair of the Transgender Working Group of the Society of Obstetricians and Gynaecologists of Canada. No other competing interests were declared.

This article has been peer reviewed.

Affiliation: Department of Obstetrics and Gynecology, Cumming School of Medicine, University of Calgary, Calgary, Alta.

Content licence: This is an Open Access article distributed in accordance with the terms of the Creative Commons Attribution (CC BY-NC-ND 4.0) licence, which permits use, distribution and reproduction in any medium, provided that the original publication is properly cited, the use is noncommercial (i.e., research or educational use), and no modifications or adaptations are made. See: https://creativecommons. org/licenses/by-nc-nd/4.0/

Correspondence to: Kimberley Thornton, kimberley.thornton@albertahealthservices.ca

CMAJ invites submissions to "Five things to know about ..." Submit manuscripts online at http://mc. manuscriptcentral.com/cmaj 